\title{
Understanding and Controlling Polymer-Organometallic Precursor Interactions in Sequential Infiltration Synthesis
}

Inbal Weisbord, ${ }^{\# \dagger}$ Neta Shomrat, ${ }^{\# \dagger}$ Rotem Azoulay, ${ }^{\dagger}$ Alexander Kaushansky, $†$ Tamar SegalPeretz ${ }^{\dagger}$

$\dagger$ The Wolfson Department of Chemical Engineering, Technion - Israel Institute of Technology, Haifa 3200003, Israel.

$\ddagger$ Schulich Faculty of Chemistry, Technion - Israel Institute of Technology, Haifa 3200003, Israel.

\#- These authors contributed equally to this work

\section{Supporting Information}

\subsection{Quantum mechanical calculations and in-situ growth measurements in homopolymer systems}

All calculations used mPMMA and mP2VP models for PMMA and P2VP polymers, respectively, due to their structural similarities to the repeating units of the polymers (Figure S1). mP2VP has only one Lewis base site that can interact with a Lewis acid (TMA), namely a nitrogen atom, while, mPMMA has two such sites, $\mathrm{MeO}$ - and $\mathrm{C}=\mathrm{O}$. Calculated Gibbs free energies and enthalpies indicated that complexation via $\mathrm{C}=\mathrm{O}$ (Scheme 1, Path a) is preferable to $\mathrm{MeO}$ - (Scheme 1, Path b) by $11.2 \mathrm{kcal} / \mathrm{mol}$. Thus, all further calculations of complexation energies of mPMMA with TMA were performed for interactions with the favorable $\mathrm{C}=\mathrm{O}$ site.

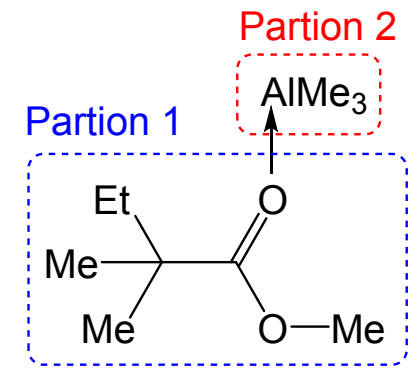

MPMMA-TMA

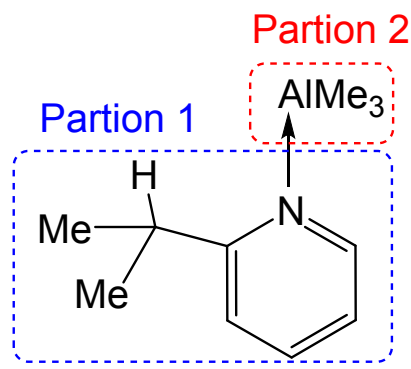

MP2VP.TMA

Figure S1: The chemical structures of the models used in calculations 

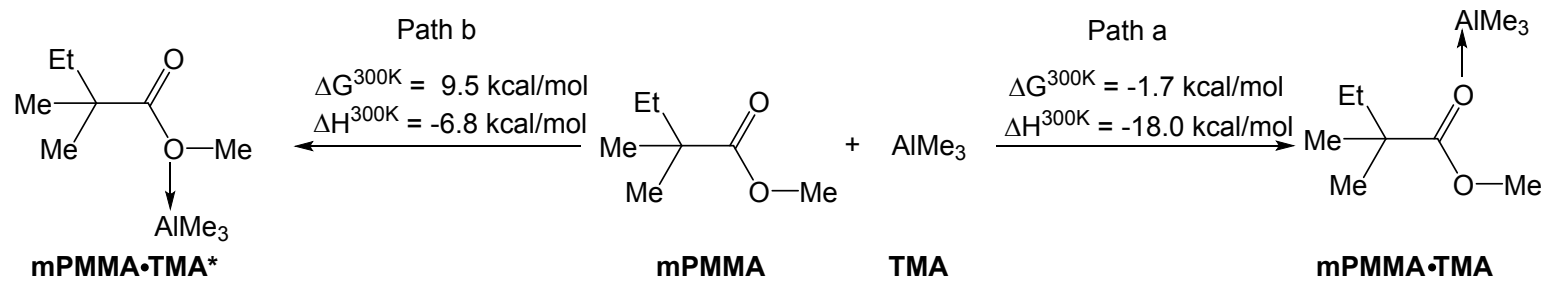

Figure S2: Calculated Gibbs free energy and enthalpy of complexation reaction via $(C=O)$ and $(\mathrm{MeO}-)$, path a and path $b$, respectively.

The basis set superposition error (BSSE) was evaluated using the counterpoise correction method $^{1}$ as a single point energy calculation at the M062X/6-311+G(2d,2p) optimized ground state complexes at $300 \mathrm{~K}$. For the BSSE evaluation, the complexes were partitioned into two fragments: mPMMA and TMA for the mPMMA•TMA complex, and $\mathrm{mP2VP}$ and TMA for the mP2VP $\bullet$ TMA complex. This results in BSSE corrections of 0.88 and $0.73 \mathrm{kcal} / \mathrm{mol}$ for $\mathrm{mPMMA} \bullet \mathrm{TMA}$ and $\mathrm{mP} 2 \mathrm{VP} \cdot \mathrm{TMA}$, respectively.

Calculations of single point energy (with $6-311+\mathrm{G}(2 \mathrm{~d}, 2 \mathrm{p})$ basis set) were carried out using additional functions known for their accuracy in estimating bonding energies. Gibbs free energies of complexation reactions were evaluated using thermodynamic parameters calculated with the M062X functional at $300 \mathrm{~K}$. Based on Table S1, it is evident that the deviations of energies calculated using other functions are within chemical accuracy, relative to M062X ( \pm 1 $\mathrm{kcal} / \mathrm{mol})$.

\begin{tabular}{|c|c|c|c|c|}
\hline$\Delta \mathrm{G}[\mathrm{kcal} / \mathrm{mol}]$ & M06-2X & B3LYP D3bj & CAM-B3LYP D3bj & wB97XD \\
\hline P2VP & -9.4 & -8.7 & -8.4 & -8.8 \\
\hline PMMA & -1.7 & -0.8 & -1.3 & -1.4 \\
\hline
\end{tabular}

Table S1: Single point energy calculations

The change in enthalpy at a given temperature is calculated by subtracting the respective enthalpies of the reactants from that of the products (Eq. S1) At the studied temperature range, this difference varied weakly with temperature. Entropy per molecule is represented by the ratio between $\Delta \mathrm{H}$ and the thermal energy $k \mathrm{~T}$ (where $k$ is Boltzmann constant). In this temperature range, the thermal energy was negligible compared with $\Delta \mathrm{H}$, meaning that the entropy was approximately constant with temperature. Since both values were weak functions of temperature, average values were used. 


\subsection{Geometries and energies of the calculated structures}

A search for the lowest energy conformers was carried out at the M06-2X/6$311+\mathrm{G}(2 \mathrm{~d}, 2 \mathrm{p})$ level of theory by rotation of free dihedral angles for each structure. Thermodynamic parameters were calculated at $300 \mathrm{~K}$.

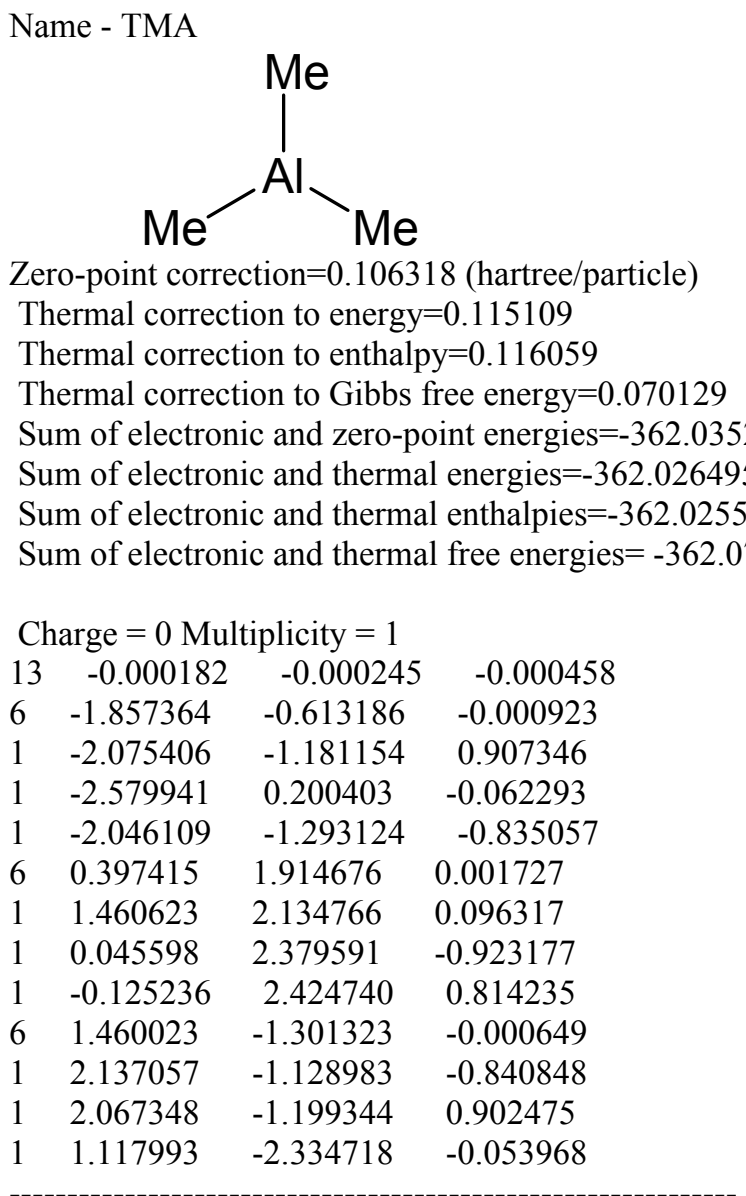

Name- mP2VP

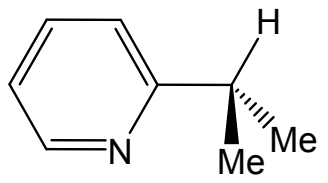

Zero-point correction $=0.174140$ (hartree/particle)

Thermal correction to energy $=0.182699$

Thermal correction to enthalpy $=0.183649$

Thermal correction to Gibbs free energy $=0.140432$

Sum of electronic and zero-point energies $=-365.999645$

Sum of electronic and thermal energies $=-365.991086$

Sum of electronic and thermal enthalpies $=-365.990136$

Sum of electronic and thermal free energies $=-366.033353$
Charge $=0$ Multiplicity $=1$
$6 \quad 1.595609-1.299300$
$\begin{array}{llll}6.567352 & -0.307573 & 0.000059\end{array}$ 


$\begin{array}{llll}1 & 1.882081 & -2.344777 & 0.000394 \\ 6 & 0.788469 & 1.281554 & -0.000217 \\ 6 & 2.148537 & 1.013067 & -0.000166 \\ 1 & 3.615561 & -0.568538 & 0.000108 \\ 1 & 0.423052 & 2.299226 & -0.000391 \\ 1 & 2.867198 & 1.821401 & -0.000303 \\ 7 & 0.289837 & -1.051347 & 0.000171 \\ 6 & -1.609699 & 0.452807 & -0.000088 \\ 1 & -1.776987 & 1.532065 & -0.000295 \\ 6 & -2.241399 & -0.145619 & 1.258510 \\ 1 & -3.317389 & 0.028879 & 1.263725 \\ 1 & -2.062391 & -1.220117 & 1.282506 \\ 1 & -1.816455 & 0.291315 & 2.162143 \\ 6 & -2.241404 & -0.146104 & -1.258451 \\ 1 & -3.317400 & 0.028359 & -1.263710 \\ 1 & -1.816492 & 0.290508 & -2.162255 \\ 1 & -2.062364 & -1.220606 & -1.282053 \\ -------------------------------------------------------\end{array}$<smiles>CCCCC(C)[C@H](C)c1cccc[n+]1[Al](C)C</smiles>

Zero-point correction $=0.283383$ (hartree/particle)

Thermal correction to energy $=0.301235$

Thermal correction to enthalpy $=0.302185$

Thermal correction to Gibbs free energy $=0.237438$

Sum of electronic and zero-point energies $=-728.075094$

Sum of electronic and thermal energies $=-728.057241$

Sum of electronic and thermal enthalpies $=-728.056291$

Sum of electronic and thermal free energies $=-728.121038$

Charge $=0$ Multiplicity $=1$
\begin{tabular}{llll}
13 & -1.901799 & -0.208838 & \multicolumn{1}{l}{-0.013205} \\
6 & -0.029310 & 2.056268 & 0.009559 \\
6 & 1.126168 & 0.045579 & -0.015470 \\
6 & 1.134174 & 2.796995 & 0.017118 \\
1 & -0.999129 & 2.531800 & 0.015384 \\
6 & 2.335226 & 0.738410 & -0.007155 \\
6 & 2.344826 & 2.119436 & 0.009013 \\
1 & 1.085251 & 3.874928 & 0.029099 \\
1 & 3.260471 & 0.180911 & -0.011934 \\
1 & 3.280598 & 2.661135 & 0.015483 \\
7 & -0.040292 & 0.713580 & -0.006228 \\
6 & -1.859364 & -1.245407 & -1.708424 \\
1 & -1.600058 & -2.299334 & -1.579138 \\
1 & -2.837243 & -1.220556 & -2.196074 \\
1 & -1.148302 & -0.826323 & -2.427329 \\
6 & -3.138245 & 1.340319 & -0.035001 \\
1 & -4.160397 & 0.950677 & -0.056197 \\
1 & -3.077642 & 1.980154 & 0.849770 \\
1 & -3.041203 & 1.979013 & -0.917548
\end{tabular}




$\begin{array}{llll}6 & -1.884582 & -1.215429 & 1.697628 \\ 1 & -1.379738 & -0.660959 & 2.494720 \\ 1 & -2.908523 & -1.381094 & 2.043550 \\ 1 & -1.412424 & -2.199419 & 1.639397 \\ 6 & 1.116253 & -1.464562 & -0.017614 \\ 1 & 0.084121 & -1.793002 & -0.093041 \\ 6 & 1.686751 & -2.001268 & 1.298855 \\ 1 & 1.632379 & -3.089541 & 1.307567 \\ 1 & 2.732759 & -1.715065 & 1.420764 \\ 1 & 1.121435 & -1.624480 & 2.150448 \\ 6 & 1.868875 & -2.022341 & -1.228208 \\ 1 & 1.787279 & -3.108698 & -1.239947 \\ 1 & 1.451853 & -1.639547 & -2.158999 \\ 1 & 2.929314 & -1.768771 & -1.192525 \\ --------------------------------------------------------\end{array}$<smiles>CCC(C)(C)C(=O)OC</smiles>

Zero-point correction $=0.204983$ (hartree/particle)

Thermal correction to energy $=0.216189$

Thermal correction to enthalpy $=0.217139$

Thermal correction to Gibbs free energy $=0.168256$

Sum of electronic and zero-point energies $=-425.382415$

Sum of electronic and thermal energies $=-425.371209$

Sum of electronic and thermal enthalpies $=-425.370259$

Sum of electronic and thermal free energies $=-425.419142$

\begin{tabular}{|c|c|c|c|}
\hline \multicolumn{3}{|c|}{ Charge $=0$ Multiplicity $=1$} & \\
\hline 8 & 1.421580 & 1.291887 & -0.677392 \\
\hline 6 & 0.881299 & 0.365855 & -0.134470 \\
\hline 8 & 1.544054 & -0.748133 & 0.222534 \\
\hline 6 & 2.934305 & -0.753019 & -0.098924 \\
\hline 1 & 3.440666 & 0.070096 & 0.400679 \\
\hline 1 & 3.316677 & -1.706073 & 0.250941 \\
\hline 1 & 3.074286 & -0.653241 & -1.173269 \\
\hline 6 & -0.599402 & 0.285268 & 0.210291 \\
\hline 6 & -1.232222 & 1.644051 & -0.079380 \\
\hline 1 & -2.276130 & 1.644647 & 0.230634 \\
\hline 1 & -0.711864 & 2.432017 & 0.462904 \\
\hline 1 & -1.178132 & 1.882324 & -1.140914 \\
\hline 6 & -0.748024 & -0.066926 & 1.696363 \\
\hline 1 & -0.347237 & -1.056715 & 1.907400 \\
\hline 1 & -0.220068 & 0.657881 & 2.317153 \\
\hline 1 & -1.798669 & -0.044155 & 1.982640 \\
\hline 6 & -1.202097 & -0.820773 & -0.687070 \\
\hline 1 & -0.964100 & -0.583976 & -1.727722 \\
\hline 1 & -0.700091 & -1.760736 & -0.454268 \\
\hline 6 & -2.711016 & -0.999401 & -0.549415 \\
\hline 1 & -3.252644 & -0.103427 & -0.849173 \\
\hline 1 & -3.048695 & -1.816010 & -1.186243 \\
\hline & -2.996123 & -1.242989 & 0.473736 \\
\hline
\end{tabular}




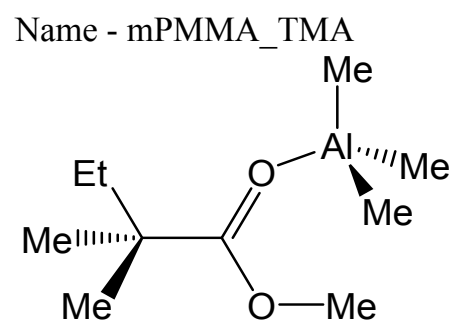

Zero-point correction $=0.313583$ (hartree/particle)

Thermal correction to energy $=0.334264$

Thermal correction to enthalpy $=0.335214$

Thermal correction to Gibbs free energy $=0.264373$

Sum of electronic and zero-point energies $=-787.447516$

Sum of electronic and thermal energies $=-787.426835$

Sum of electronic and thermal enthalpies $=-787.425885$

Sum of electronic and thermal free energies $=-787.496726$

\begin{tabular}{llll}
\multicolumn{5}{c}{ Charge $=0$ Multiplicity $=1$} \\
13 & -2.094819 & -0.592437 & 0.011626 \\
8 & -0.586449 & 0.670368 & -0.063096 \\
6 & 0.596788 & 0.978141 & -0.040059 \\
8 & 0.944678 & 2.237288 & -0.175101 \\
6 & -0.132457 & 3.179434 & -0.325063 \\
1 & -0.773544 & 3.149507 & 0.552199 \\
1 & 0.344941 & 4.146493 & -0.429431 \\
1 & -0.717221 & 2.933084 & -1.207235 \\
6 & 1.734600 & 0.007142 & 0.185061 \\
6 & 1.735196 & -0.265261 & 1.702390 \\
1 & 2.536180 & -0.961894 & 1.943870 \\
1 & 1.914641 & 0.655048 & 2.259265 \\
1 & 0.787060 & -0.696086 & 2.021462 \\
6 & 3.071142 & 0.615596 & -0.238693 \\
1 & 3.096705 & 0.809178 & -1.311418 \\
1 & 3.263262 & 1.550364 & 0.282975 \\
1 & 3.873770 & -0.078157 & 0.003688 \\
6 & 1.406066 & -1.276191 & -0.606714 \\
1 & 0.492828 & -1.706542 & -0.198315 \\
1 & 1.180639 & -1.006340 & -1.641670 \\
6 & 2.509802 & -2.328112 & -0.589876 \\
1 & 2.793854 & -2.601512 & 0.426168 \\
1 & 2.159525 & -3.232173 & -1.085005 \\
1 & 3.402584 & -1.990630 & -1.114205 \\
6 & -1.731511 & -1.663943 & 1.638227 \\
1 & -2.623833 & -2.247604 & 1.883972 \\
1 & -0.911469 & -2.381157 & 1.551123 \\
1 & -1.531437 & -1.037211 & 2.512160 \\
6 & -3.532040 & 0.749167 & 0.185703 \\
1 & -3.568044 & 1.417225 & -0.679587 \\
1 & -4.520945 & 0.292239 & 0.271153 \\
1 & -3.398233 & 1.373687 & 1.073663 \\
6 & -1.936882 & -1.488102 & -1.746327 \\
1 & -2.915742 & -1.830865 & -2.091663 \\
1 & -1.563494 & -0.803032 & -2.513614 \\
1 & -1.279430 & -2.360402 & -1.743003
\end{tabular}


1.3 Calculated thermodynamic values

\begin{tabular}{|c|c|c|c|c|c|c|c|c|}
\hline \multirow{2}{*}{$\mathrm{T}[\mathrm{K}]$} & \multicolumn{2}{|c|}{$\Delta \mathrm{H}[\mathrm{kcal} / \mathrm{mol}]$} & \multicolumn{2}{c|}{$\Delta \mathrm{S}[\mathrm{kcal} / \mathrm{K} \cdot \mathrm{mol}]$} & \multicolumn{2}{c|}{$\mathrm{T} \Delta \mathrm{S}[\mathrm{kcal} / \mathrm{mol}]$} & \multicolumn{2}{c|}{$\Delta \mathrm{G}[\mathrm{kcal} / \mathrm{mol}]$} \\
\cline { 2 - 9 } & PMMA & P2VP & PMMA & P2VP & PMMA & P2VP & PMMA & P2VP \\
\hline 300 & -18.0 & -24.7 & -0.055 & -0.051 & -16.3 & -15.3 & -1.7 & -9.4 \\
\hline 330 & -17.9 & -24.7 & -0.054 & -0.051 & -17.8 & -16.7 & -0.1 & -7.9 \\
\hline 360 & -17.8 & -24.6 & -0.054 & -0.050 & -19.3 & -18.2 & 1.5 & -6.4 \\
\hline 390 & -17.7 & -24.5 & -0.053 & -0.050 & -20.8 & -19.6 & 3.1 & -4.9 \\
\hline 420 & -17.6 & -24.4 & -0.053 & -0.050 & -22.3 & -21.0 & 4.7 & -3.4 \\
\hline 460 & -17.4 & -24.2 & -0.053 & -0.050 & -24.2 & -22.8 & 6.8 & -1.4 \\
\hline 500 & -17.3 & -24.1 & -0.052 & -0.049 & -26.1 & -24.7 & 8.8 & 0.6 \\
\hline Average & -17.7 & -24.4 & -0.053 & -0.050 & & & & \\
\hline
\end{tabular}

Table S2: $\Delta \mathrm{S}$ and $\Delta \mathrm{H}$ values calculated using quantum mechanical calculations at different temperatures. Gibbs free energy was calculated using Gibbs fundamental equation.

Eq. S1 $\Delta_{r} H_{T}=\sum H_{\text {Prod }, T}-\sum H_{\text {Reac }, T}=\sum\left(H_{\text {Prod }, 298}+\int_{298}^{T} C_{\text {Prod }} d T\right)-\sum\left(H_{\text {Reac }, 298}+\int_{298}^{T} C_{P_{\text {Reac }}} d T\right)$

\subsection{Typical mass gain behavior during static TMA exposure}

Pressure stability in the chamber was tested before each experiment in a rate of rise test. In the test, $\mathrm{N}_{2}$ flow was reduced to 0 , followed by closing inlet and outlet valves. The rate of rise in pressure was averaged over two minutes. Working rate of rise did not surpass 50 $\mathrm{mTorr} / \mathrm{min}$. In all experiments, maximal pressure increases due to imperfect sealing were below 10 Torr.

The pressure in the system is constantly measured via a Pirani gauge. While the pressure profile is reproduceable and reliable, the absolute values are not accurate due to continuous deposition of metal oxides on the Pirani gauge. In order to accurately probe the pressure in the chamber, a capacitance manometer pressure gauge (Baratron) was added to the system and the Pirani and Baratron pressure measurements were compared. Figure S3 shows a comparison between the pressure reading of the two gauges at the following conditions: (a) with various $\mathrm{N}_{2}$ flows, and (b) during static mode with $\mathrm{N}_{2}$. The values plotted in Figure S3 (a) are also presented in Table S3.

The comparison shows that the Pirani gauge measurements are approximately an order of magnitude higher than the Baratron gauge measurements. Since we do not expose the 
Baratron to any precursor, we concluded that the actual pressure in the chamber is an order of magnitude lower than the Pirani measurements.
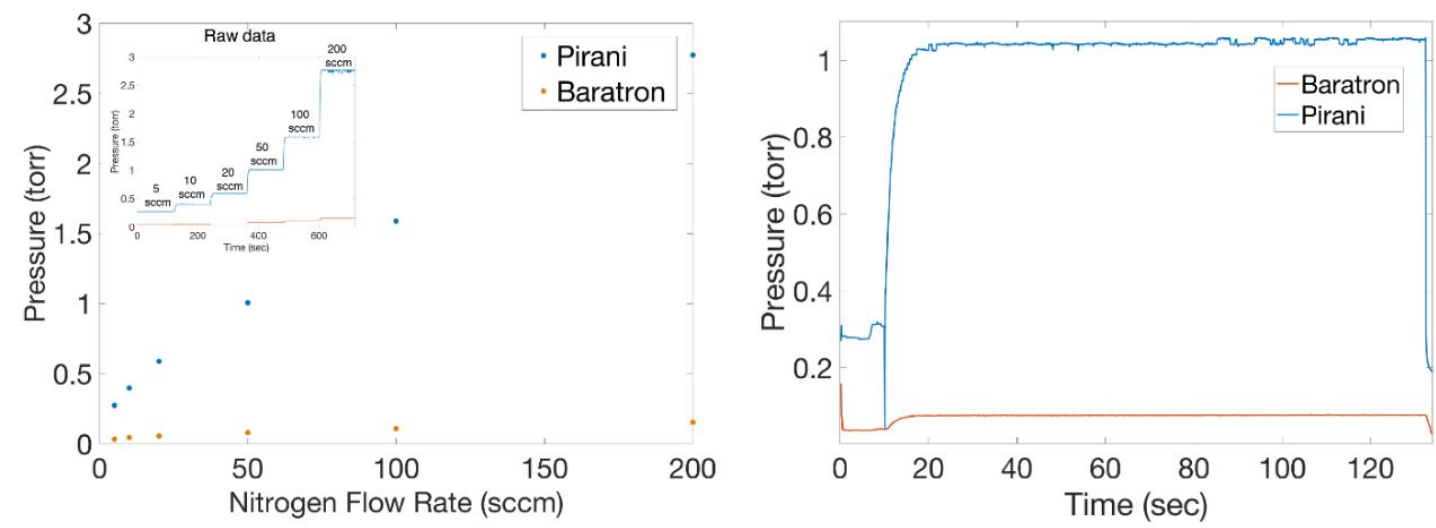

Figure S3: Comparison between Pirani and Baratron pressures measurements in: (a) various $\mathrm{N}_{2}$ flows, at chamber temperature of $95^{\circ} \mathrm{C}$, and (b) static mode with $\mathrm{N}_{2}$ (without precursor exposure).

\begin{tabular}{|c|c|c|c|c|c|c|}
\hline Nitrogen Flow Rate (sccm) & 5 & 10 & 20 & 50 & 100 & 200 \\
\hline Baratron (torr) & 0.035 & 0.046 & 0.057 & 0.080 & 0.11 & 0.15 \\
\hline Pirani (torr) & 0.27 & 0.40 & 0.59 & 1.0 & 1.6 & 2.8 \\
\hline
\end{tabular}

Table S3: Comparison between Pirani and Baratron pressures measurements, values presented in Figure S3(a).

Figure S4 presents two typical mass and pressure behaviors for (a) uncoated quartz, and (b) a polymer-coated sample. For bare quartz, the mass gain follows a typical surface coverage trend, which ultimately reaches a constant value. When working with a polymer layer, on the other hand, a different typical behavior is observed. This behavior is discussed in Section 3.3.1 of the paper. The pressure was measured using Pirani gauge. The measured pressure values are estimated to be one order of magnitude larger than absolute values in the chamber, as discussed above. 

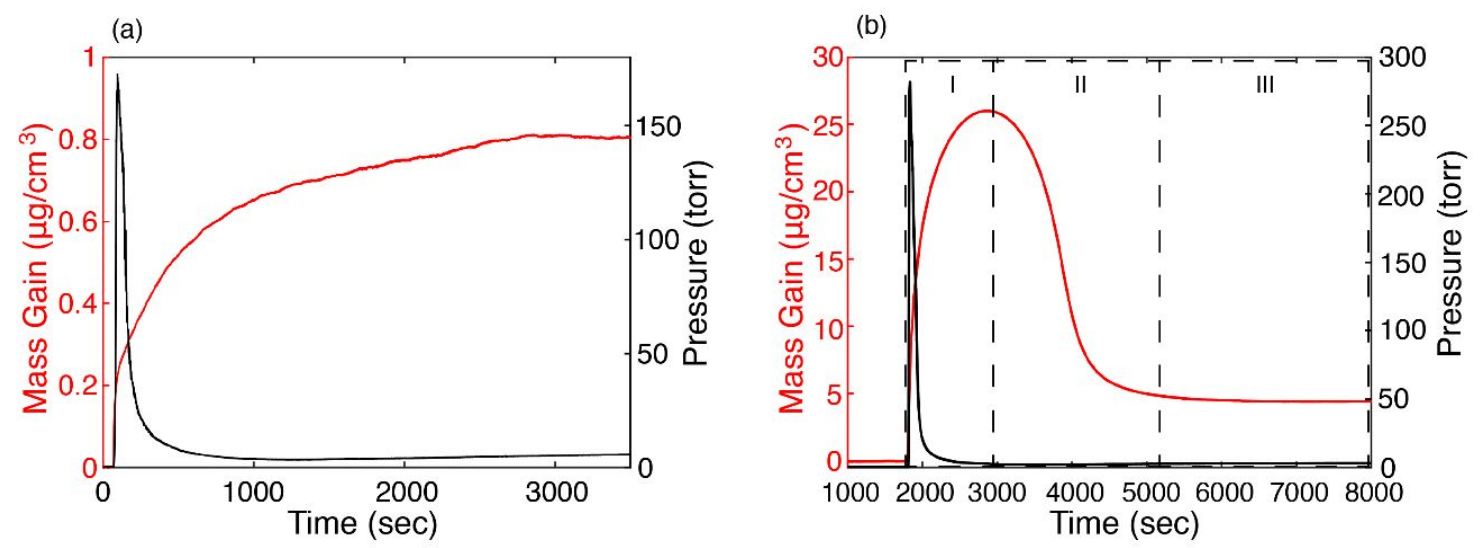

Figure S4: A typical dose-and-hold TMA pulse at $150^{\circ} \mathrm{C}$ on (a) bare sample without polymer, (b) $750 \mathrm{~nm}$ of $\mathrm{P} 2 \mathrm{VP}$ polymer. Pressure and mass gain are presented for each sample. The mass gained on the polymer film is divided to three regions: (I) mass increase as a result of TMA exposure and pressure elevation; (II) mass decrease due to TMA absorption and pressure decrease; and (III) mass and pressure stabilization and thermodynamic equilibrium.
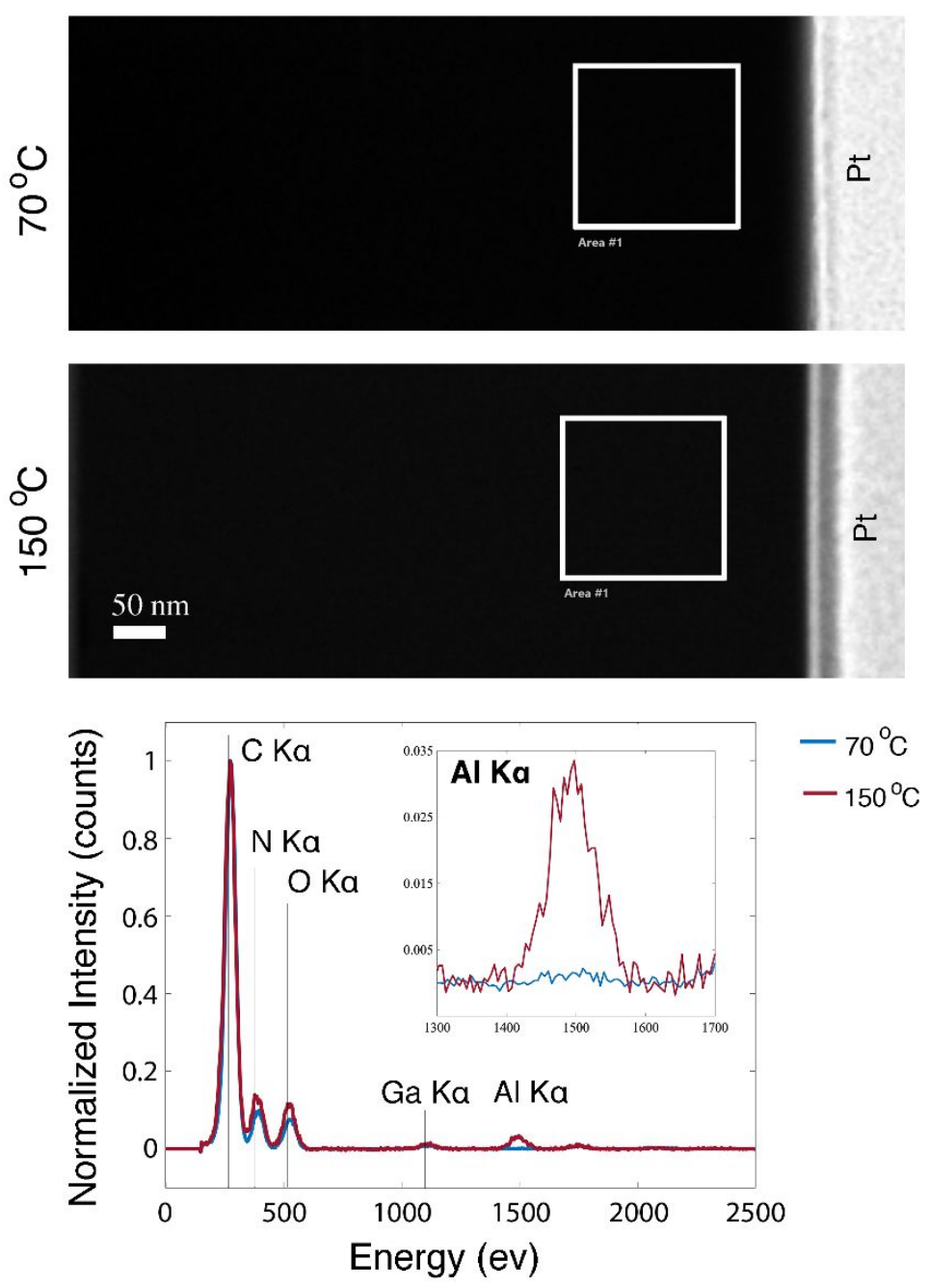

Figure S5: Elemental analysis of 1 cycle of $\mathrm{AlO}_{\mathrm{x}}$ SIS in P2VP, grown at steady state conditions (1 hour exposure): (a) high angle annular dark field (HAADF) scanning TEM (STEM) cross-sectional images of $\mathrm{AlO}_{\mathrm{x}}-\mathrm{P} 2 \mathrm{VP}$ when SIS was performed at $70^{\circ} \mathrm{C}$ (top) and $150^{\circ} \mathrm{C}$ (bottom). (B) Energy dispersive X-ray spectroscopy (EDS) of the 
square are marked in (a), normalized to the carbon peak. The $\mathrm{Al} \mathrm{K} \alpha$ signal was uniform across the entire thickness of each specimen. This uniform growth indicates that the growth has reached equilibrium.

\subsection{Raw data from a single dose-and-hold TMA pulse at different temperatures}
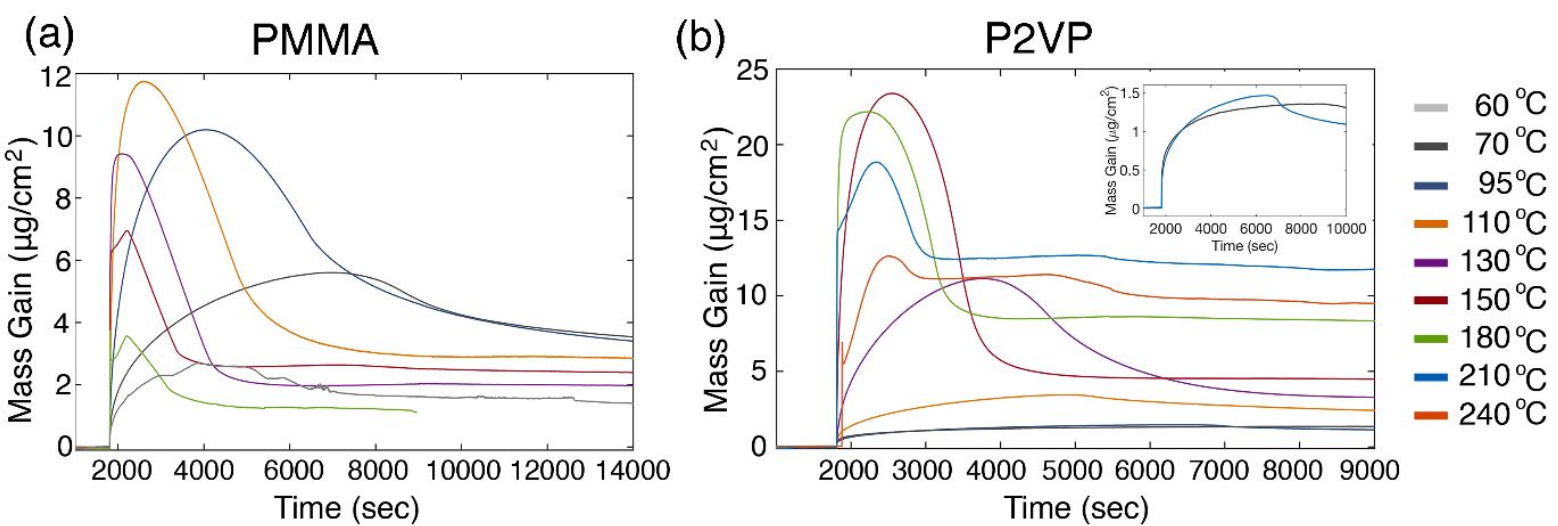

Figure S6: Raw data from dose-and-hold SIS exposure experiments of (a) TMA-PMMA and (b) TMA-P2VP at different temperatures. The typical mass peak, resulting from pressure changes in the reactor, is seen at all temperatures and appears at earlier times as the temperature increases.

\subsection{Utilizing process dynamics for controlled growth}

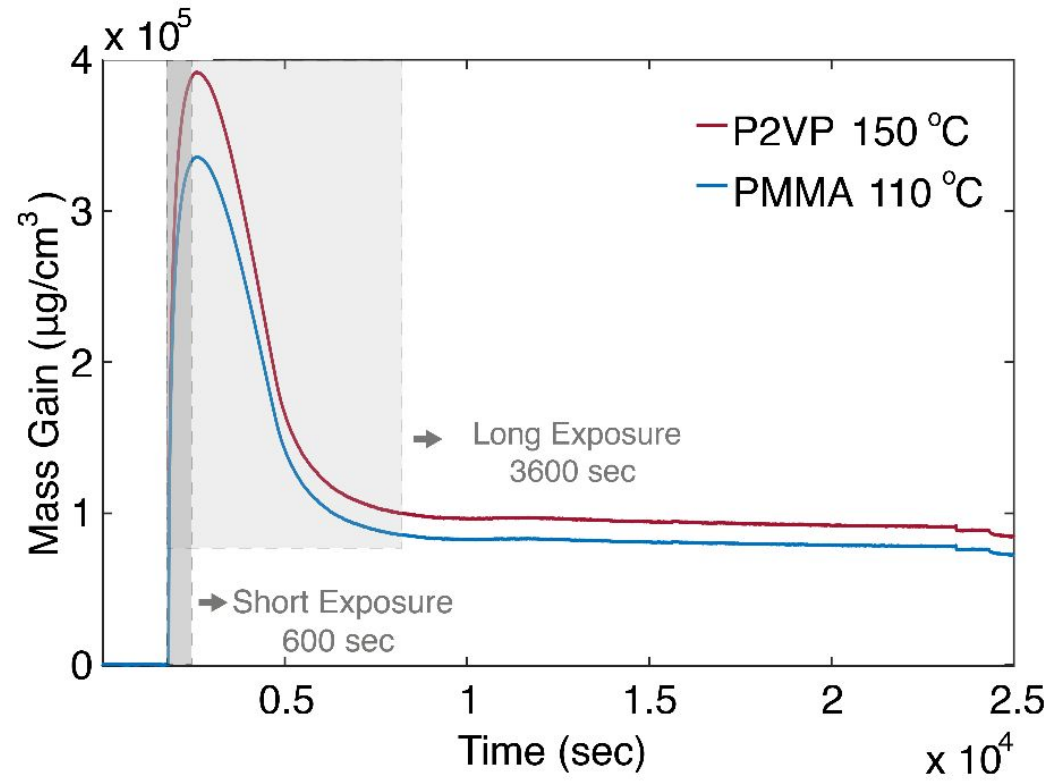

Figure S7: TMA mass gain per volume for the first long exposure $(7200 \mathrm{sec})$. Reaction temperatures were $110^{\circ} \mathrm{C}$ and $150^{\circ} \mathrm{C}$ for PMMA and P2VP, respectively. These temperatures were chosen since their maximum mass uptakes were highest among all temperatures tested. Shorter exposure times (600 sec and $3600 \mathrm{sec})$ used in the Section 3.4 were chosen based on this data, are marked by dashed lines. 


\subsection{Multi-cycle mass gain in PMMA}

PMMA exhibited a trend similar to that observed for P2VP. At short exposure times, the majority of mass accumulated during the first cycle, with little mass gained in subsequent cycles.
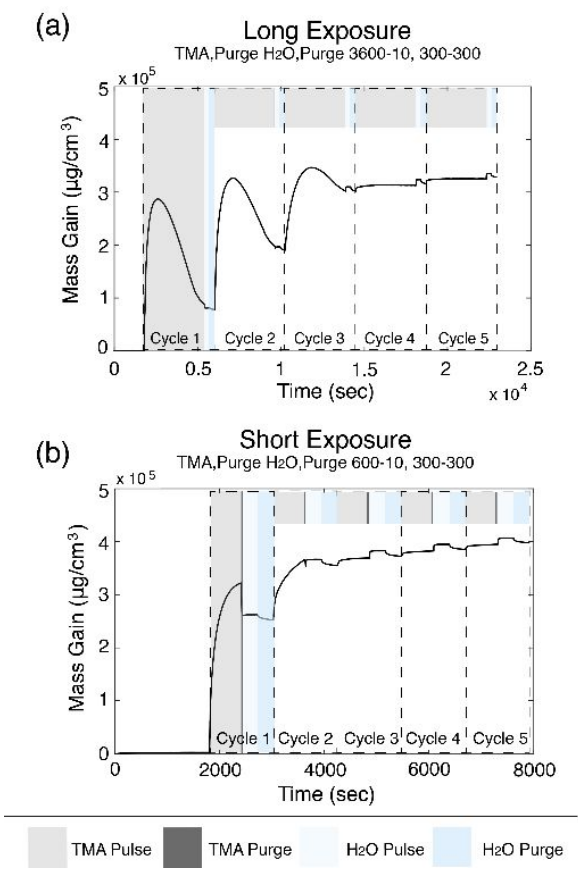

(c)
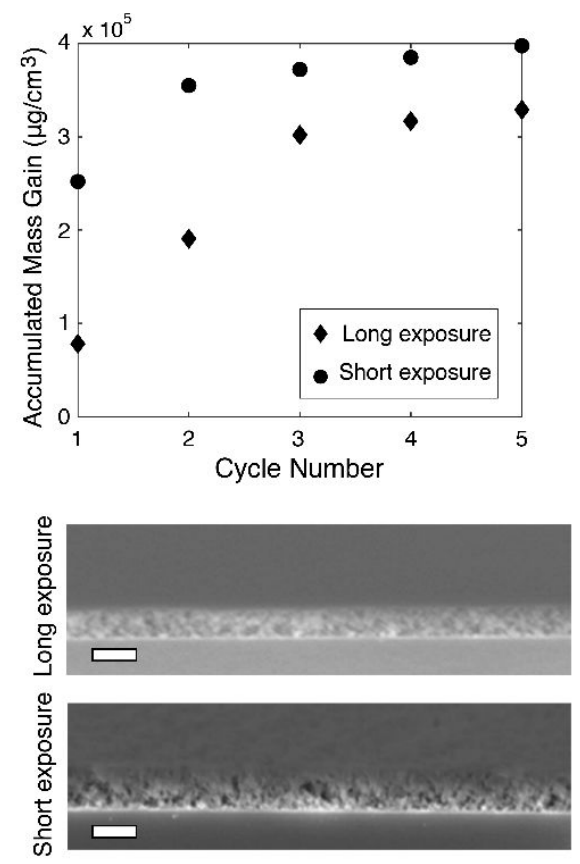

Figure S8: Multi-cycle mass gain. 5 cycles of TMA-purge:H2O-purge in P2VP system at $110^{\circ} \mathrm{C}$ under two different conditions: (a) long exposure: 3600sec-10sec:300sec-300sec and (b) short exposure: 600sec10sec:300sec-300sec. (a-b) In-situ mass gain plots; (c) Accumulated mass gain during cycles; (d) Cross-section HR-SEM images of AlOx layer after P2VP removal. The obtained thicknesses are similar: $75 \mathrm{~nm}$ and $90 \mathrm{~nm}$ for 3600-10 and 600-10 exposures, respectively. Scale bars are $100 \mathrm{~nm}$.

\subsection{Raw data of dose-and-hold TMA pulse at different temperatures in PS-b-P2VP BCP system}

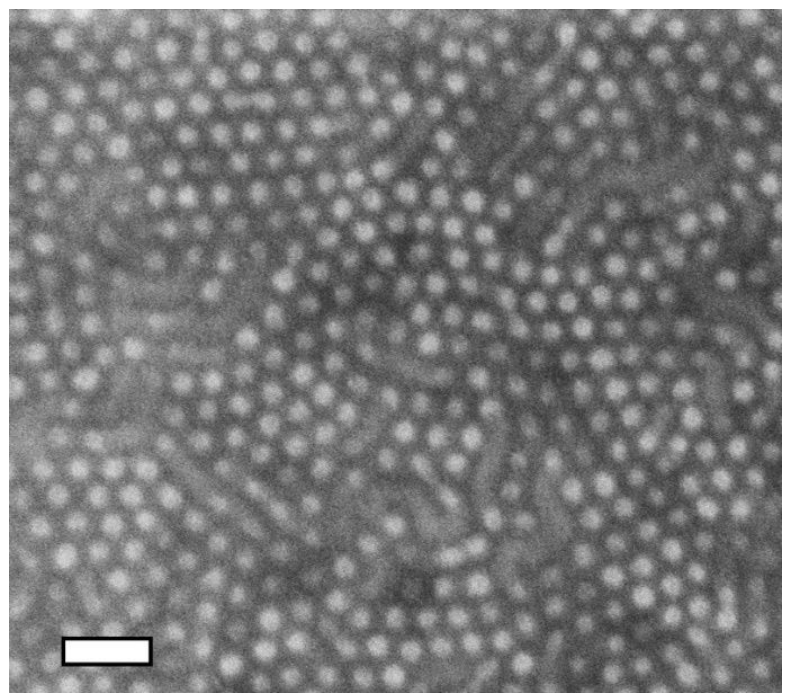

Figure S9: HR-SEM image of pristine PS- $b$-P2VP self-assembled film before SIS. Scale bar is $200 \mathrm{~nm}$. 


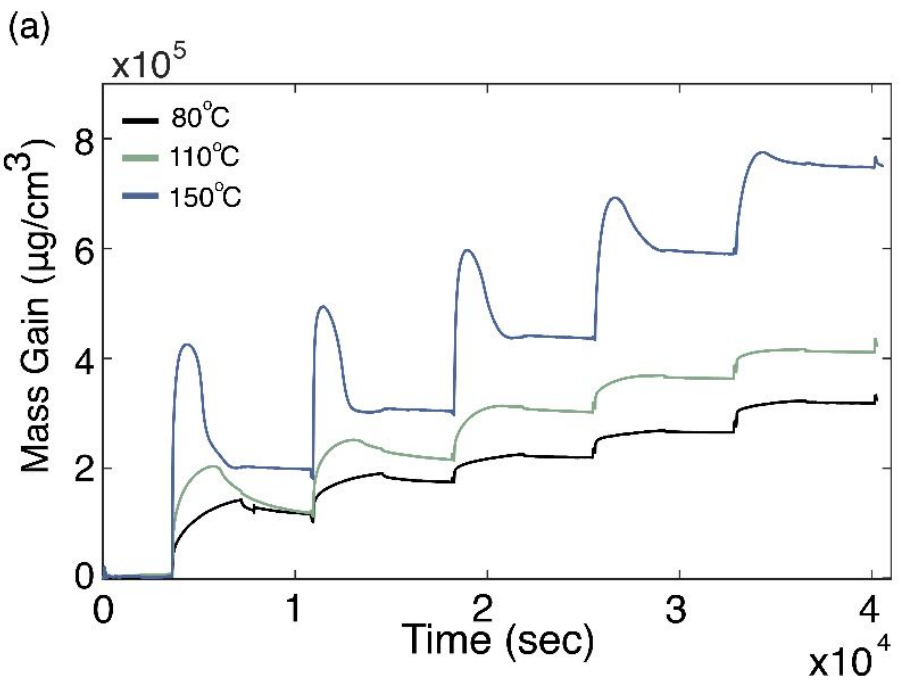

(b)

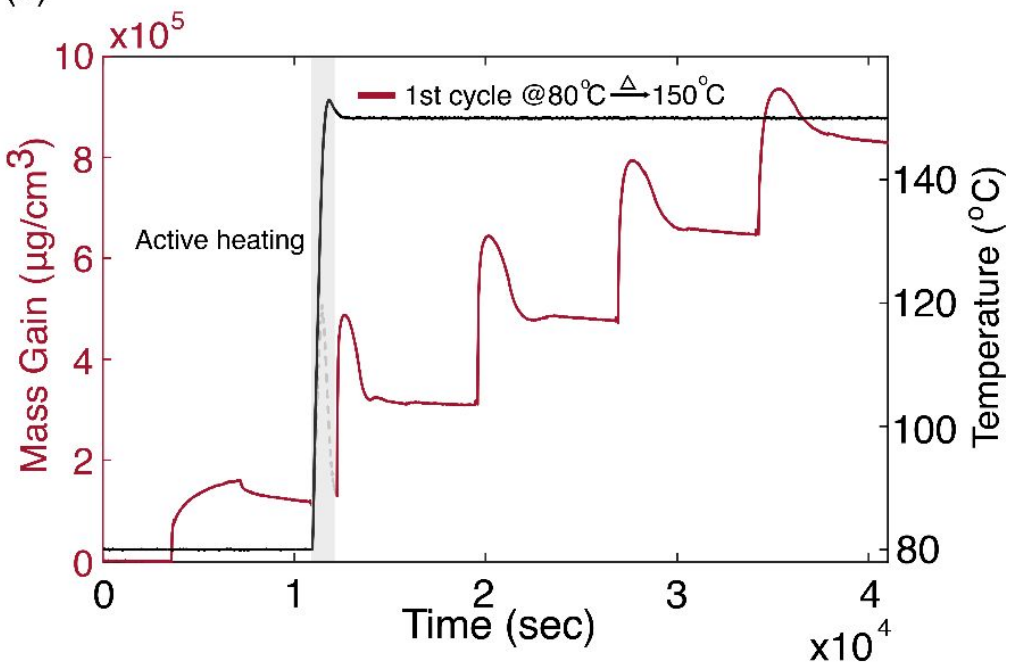

Figure S10: 5 cycles of TMA-purge: $\mathrm{H}_{2} \mathrm{O}$-purge in PS-b-P2VP system at different temperatures: (a) $80^{\circ} \mathrm{C}, 110^{\circ} \mathrm{C}$ and $150^{\circ} \mathrm{C}$; (b) First cycle at $80^{\circ} \mathrm{C}$ followed by 4 cycles at $150^{\circ} \mathrm{C}$. 


\subsection{Surface area to volume - homopolymer compared with BCP}

The ratio between surface area and volume exposed for sorption in BCP is:

SI eq. (2) $\left(\begin{array}{l}\mathrm{A} \\ \overline{\mathrm{V}}\end{array}\right)_{\mathrm{BCP}}=\frac{A_{T S}-n_{c y l} \cdot \pi \cdot\left(\frac{\left.D_{c y l}\right|^{2}}{4}-h \cdot D_{c y l}\right)}{h\left(A_{T S}-\frac{n_{c y l} \cdot \pi \cdot D_{c y l}{ }^{2}}{4}\right)}$

where:

A - Polar moiety surface area exposed to precursor sorption;

V - Polar moiety volume;

$\mathrm{A}_{\mathrm{TS}}$ - Top surface area of the film;

$\mathrm{n}_{\mathrm{cyl}}$ - Number of cylinders in $\mathrm{A}_{\mathrm{TS}}$;

$\mathrm{D}_{\text {cyl }}$ - Average cylinder diameter;

$\mathrm{H}$ - Film thickness.

The ratio of surface area to volume exposed for sorption in HP is:

SI eq.(3) $n_{c y l}=0 \rightarrow\left(\frac{\mathrm{A}}{\mathrm{V}}\right)_{\mathrm{HP}}=\frac{1}{h}$

And so the ratio between calculated ratios for $\mathrm{HP}$ and $\mathrm{BCP}$ is:

SI eq.(4) $\frac{\left(\frac{A}{\bar{v}}\right)_{B C P}}{\left(\frac{A}{\bar{v}}\right)_{\mathrm{HP}}}=\frac{A_{T S}-n_{c y l} \cdot \pi \cdot\left(\frac{D_{c y l}{ }^{2}}{4}-h \cdot D_{c y l}\right)}{A_{T S}-\frac{n_{c y l} \cdot \pi \cdot D_{c y l}{ }^{2}}{4}}$

The theoretical ratio between HP and BCP was calculated for a PS- $b$-P2VP 48k- $b$-136k system and compared with the ratio for P2VP. For the same film top surface $\left(\mathrm{A}_{\mathrm{TS}}\right), \mathrm{BCP}$ parameters were: $\mathrm{n}_{\text {cyl }}=80 \mathrm{~nm}, \mathrm{D}_{\text {cyl }}=40 \mathrm{~nm} ; \mathrm{h}=60 \mathrm{~nm}$. The calculated ratio suggests that the potential mass absorption is 18 times greater in BCP than in HP.

\subsection{Normalizing mass uptake to sample thickness}

$\underline{\text { QCM measurement accuracy }}{ }^{2}$

The Sauerbrey equation of viscoelastic films in air is:

SI eq. (5) $\frac{\Delta f}{f_{f}} \sim-\frac{2 f_{0}}{Z_{q}} \Delta m$

Where:

$\Delta f$ - Change in resonance frequency

$f_{f}$ - Fundamental frequency

$f_{0}$ - Frequency of the unloaded crystal and is equal to $f_{f} n$, where $\mathrm{n}$ is the overtone $Z_{q^{-}}$Acoustic impedance of the AT cut quartz and is equal to $8.8 \cdot 10^{6} \frac{\mathrm{kg}}{\mathrm{m}^{2} \mathrm{~s}}$ 
$\Delta m$ - Change in mass gain per unit area

Sauerbrey's equation can be used to obtain accurate results in thin-film when mass gain from the deposition causes a frequency change smaller than $2 \%$. In our study this change never exceeded $0.05 \%$.

In-situ QCM-ALD systems typically measure mass uptake per area unit, since ALD is designed for monolayer growth. As inorganic material growth in SIS occurs within polymer films, however, it is more appropriate to normalize growth to volume units. Figure S11 shows that film thickness plays a major role in the measured mass gain values. Two P2VP samples with different thicknesses $(750 \mathrm{~nm}$ and $340 \mathrm{~nm})$ were compared in a single $900 \mathrm{sec}: 900 \mathrm{sec}-$ 900sec:900sec exposure of TMA-purge: $\mathrm{H}_{2} \mathrm{O}$-purge at $150^{\circ} \mathrm{C}$. Maximum mass gain in the thick sample was approximately twice that of the thin sample; the thick sample reached maximum mass gain after 11.5 minutes while the thin sample required only $9 \mathrm{~min}$. Normalizing mass uptake to film thickness for both samples (see calculation below), yields the same mass uptake per volume unit, within the standard deviation error.

Thin film: $\frac{9.25 \frac{\mu \mathrm{g}}{\mathrm{cm}^{2}}}{\text { QCM output }} \cdot \frac{340^{-1} \mathrm{~nm}^{-1}}{\text { film thickness }} \cdot 10^{7} \frac{\mathrm{nm}}{\mathrm{cm}}=2.72 \cdot 10^{5} \frac{\mathrm{\mu g}}{\mathrm{cm}^{3}}$

Thick film: $\frac{20.7 \frac{\mathrm{\mu g}}{\mathrm{cm}^{2}}}{\text { QCM output }} \cdot \frac{750^{-1} \mathrm{~nm}^{-1}}{\text { film thickness }} \cdot 10^{7} \frac{\mathrm{nm}}{\mathrm{cm}}=2.76 \cdot 10^{5} \frac{\mathrm{\mu g}}{\mathrm{cm}^{3}}$

(a)

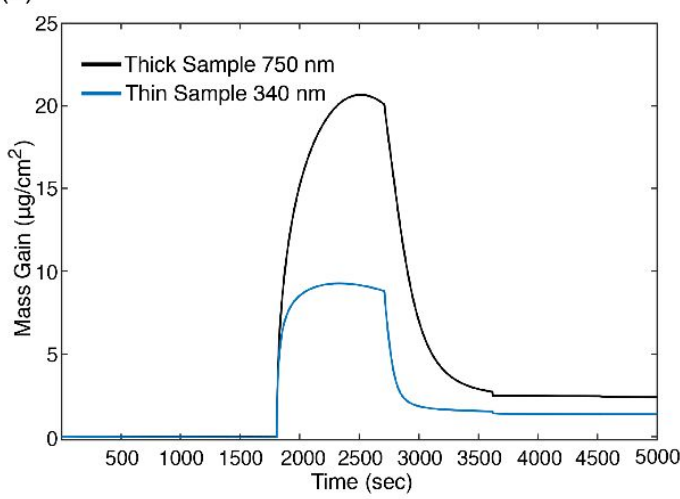

(b)

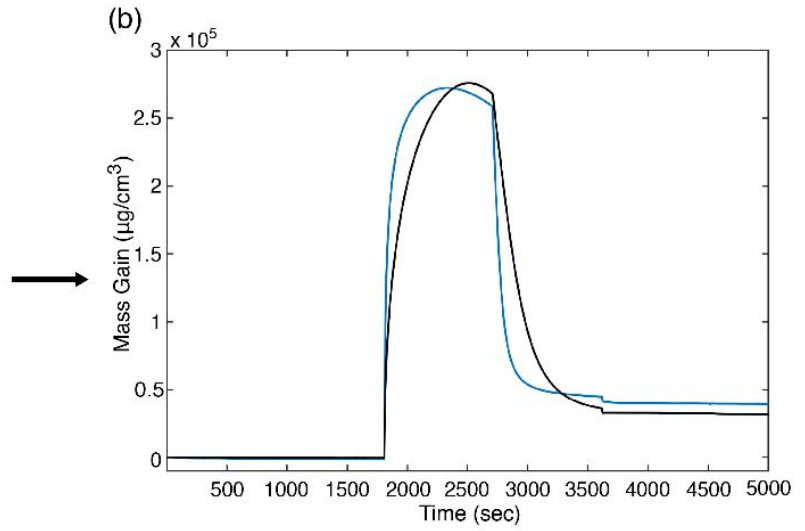

Figure S11: Mass gain of thick vs. thin P2VP layers at $150^{\circ} \mathrm{C}$. (a) Raw data as obtained from in-situ QCM per area. (b) Data normalized to film thickness. 


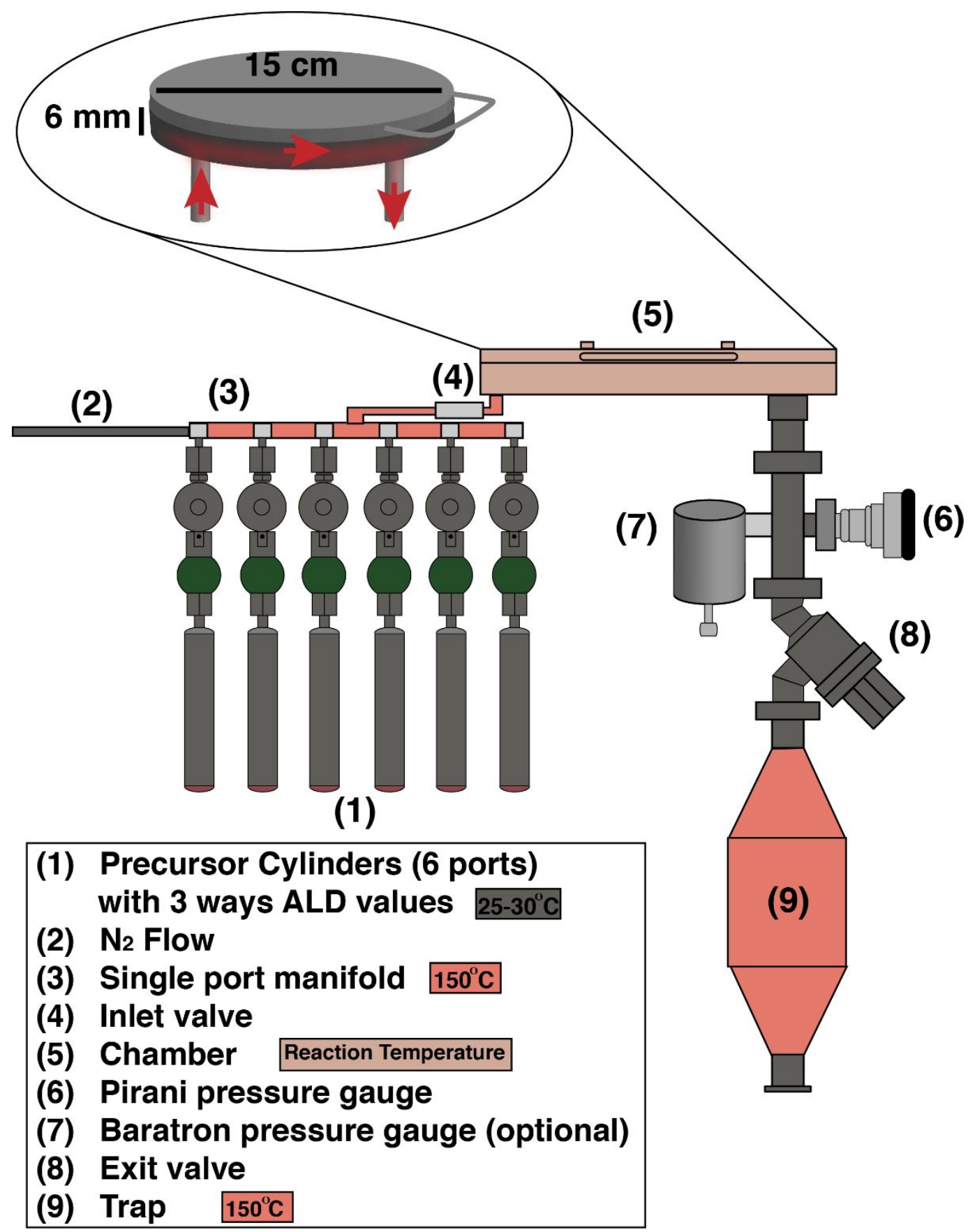

Figure S12: Schematic illustration of Savannah 100 ALD system used in this study with the relevant temperatures.

\section{$\underline{\text { References }}$}

(1) Boys, S. F.; Bernardi, F. The Calculation of Small Molecular Interactions by the Differences of Separate Total Energies. Some Procedures with Reduced Errors. Molecular Physics 1970, 19 (4), 553-566.

(2) Johannsmann D.2006.Modeling of QCM Data. Unpublished manuscript. 